\title{
Inhibitory effect of piperine on Helicobacter pylori growth and adhesion to gastric adenocarcinoma cells
}

Nagendran Tharmalingam¹, Sa-Hyun Kim², Min Park' ${ }^{1}$ Hyun Jun Woo' ${ }^{1}$ Hyun Woo Kim¹, Ji Yeong Yang ${ }^{1}$, Ki-Jong Rhee ${ }^{1}$ and Jong Bae Kim ${ }^{1 *}$

\begin{abstract}
Background: Piperine is a compound comprising 5-9\% of black pepper (Piper nigrum), which has a variety of biological roles related to anticancer activities. Helicobacter pylori has been classified as a gastric carcinogen, because it causes gastritis and gastric cancer by injecting the virulent toxin CagA and translocating VacA. The present study investigated the inhibitory action of piperine on $\mathrm{H}$. pylori growth and adhesion.

Methods: Inhibition of $H$. pylori growth was determined by the broth macrodilution method, and adhesion to gastric adenocarcinoma cells validated by urease assay. Motility test was performed by motility agar and the expression of adhesion gene and flagellar gene in response to the piperine treatment was assessed by RT-PCR and immunoblotting.

Results: Administrated piperine suppressed the level of H. pylori adhesion to gastric adenocarcinoma cells in a dose dependent manner and the inhibition was statistically significant as determined by Student's t-test. In addition, piperine treatment effects on the flagellar hook gene flgE and integral membrane component of the export apparatus gene flhA expression to be suppressed and piperine diminished the H. pylori motility.

Conclusions: $f / h A$, encodes an integral membrane component of the export apparatus, which is also one of the regulatory protein in the class 2 genes expression and flgE is one of them that encodes hook part of the flagella. Suppression of both genes, leads to less motility results in the organism attracted less towards to the gastric epithelial cells might be the possible reason in the adhesion inhibition. To our knowledge, this is the first report published on the inhibitory effects of piperine against the adhesion of $\mathrm{H}$. pylori to gastric adenocarcinoma cells.
\end{abstract}

Keywords: Piperine, Helicobacter pylori, Adhesion, Gastric cancer

\section{Background}

Helicobacter pylori is a gastric organism known for its association with chronic gastritis and peptic ulcers [1], as well as the development of gastric cancer [2]. Approximately half of the world's population harbors this gastric pathogen. According to the World Health Organization, the organism causes gastric cancer and has been classified as a class I carcinogen [3]. Adhesion to gastric epithelial cells is the initial step in $H$. pylori infection, and this organism express at least six different adhesion-associated

\footnotetext{
*Correspondence: kimjb70@yonsei.ac.kr

'Department of Biomedical Laboratory Science, College of Health Sciences, Yonsei University, Wonju, Republic of Korea

Full list of author information is available at the end of the article
}

factors; AlpA-B (adherence-associated lipoprotein A and B), BabA (blood group antigen-binding adhesion), SabA (sialic acid-binding adhesion), HopZ (H. pylori outer membrane protein), HpaA (H. pylori adhesin A) and Lewis ${ }^{\mathrm{x}}$-LPS, all of which mediate adhesion to gastric epithelial cells, followed by the establishment of infection [4]. Motility plays a vital role in colonization also it enhances H. pylori adhesion, and the motility is mediated by the sheathed flagella [5]. H. pylori flagellin is encoded by flaA and flaB to form filament, which is the part of flagella. This filament connects to the hook encoded by flgE. flh $A$ encodes an integral membrane component of the export apparatus and regulates the expression of FlaA and FlaB [6]. Once an infection has commenced, the CagA protein 
is injected into epithelial cells via type IV secretion system [7] which then initiates multistep carcinogenesis [8].

Natural compounds or food supplements are now considered to be important substances studied for their anticancer activities during initiation, development and progression of cancer. Black pepper (Piper nigrum) is known as the "king of spices" and has been reported to have beneficial effects on common colds, coughs, dyspnea, throat diseases, intermittent fevers, colic, and dysentery. Traditionally, it has been used to treat inflammation [9]. Piperine, a nitrogenous substance that is abundantly present in black pepper, exhibits various roles in lipid and drug metabolism, bioavailability of drugs, and expresses antimutagenic and tumor-inhibiting effects as an antioxidant with influence on the gastrointestinal system [10]. Several researchers have reported that piperine has a role in anticancer activity as studied in various cancer cell lines, such as the inhibition of lung metastasis [11] and inhibition of prostate cancer [12]. In this study, we observed that piperine has a potential role in the growth inhibition of $H$. pylori and based on this observation, we hypothesized that, if piperine inhibits bacterial growth, it may also have a role in protecting against bacterial infection. Adhesion is the initial step in $H$. pylori infection and we used this factor as the rationale of our study. Our results demonstrated that piperine actively inhibits $H$. pylori adhesion, which was confirmed by urease assay and RT- PCR, immunoblotting and motility by motility agar test. To the best of our knowledge, this is the first report of piperine actively inhibiting $H$. pylori growth and adhesion.

\section{Results}

\section{Effect of piperine on growth inhibition}

H. pylori strains 60190, NTCC 11637 and Tx30a were used in this study to determine the inhibitory action of piperine against $H$. pylori growth. The minimum concentration required to inhibit the complete growth of the H. pylori was found to be $125 \mu \mathrm{M}$ (Figure 1A - C) determined by the broth macrodilution method. To confirm this finding, the agar dilution method was performed and the minimal inhibitory concentration of piperine on H. pylori growth was found to be same with broth macrodilution method (data not shown). For further experiments, $100 \mu \mathrm{M}$ of piperine was administered at a sub-MIC concentration.

\section{Half maximal inhibitory concentration ( $\left(\mathrm{C}_{50}\right)$}

H. pylori 60190 was used in this study to determine $\mathrm{IC}_{50}$ of the piperine which is defined as a measure of effectiveness of a compound in inhibiting biological or biochemical function. The quantitative measure indicates concentration of inhibiting compound required for given biological or biochemical function by half. $H$. pylori was treated with piperine at $50 \sim 150 \mu \mathrm{M}$. As shown in
Figure 2 (Figure 2) the dose dependent decrease in the bacterial growth by piperine was expressed as a percentage and the $\mathrm{IC}_{50}$ value was found to be $115 \mu \mathrm{M}$ from $\log$ concentrations of piperine in normalized response with variable slope.

\section{Effect of piperine on adhesion inhibition}

H. pylori strain 60190 was used to determine whether piperine could inhibit adhesion of $H$. pylori to gastric epithelial cells. Piperine treatment at concentrations of 50, 75, 100 and $125 \mu \mathrm{M}$ were applied during H. pylori infection for 2 hours, which reduced the adhesion of H. pylori to the AGS cells. Concentrations of 125 and $100 \mu \mathrm{M}$ showed the least adhesion (Figure 3A) and potential bacterial adhesion inhibition was statistically highly significant $(\mathrm{p}<0.01)$. At a concentration of $75 \mu \mathrm{M}$, significant inhibition $(\mathrm{p}<0.05)$ was observed, but $50 \mu \mathrm{M}$ did not appear to cause significant inhibition (Figure $3 \mathrm{~A}$ ). The results were similar at both 100 and $200 \mathrm{MOI}$ and the adhesion of $H$. pylori to AGS cells was inversely proportional to the amount of piperine treatment. In summary, bacterial adhesion was reduced by piperine in a dose-dependent manner.

The minimum inhibitory concentration of piperine on H. pylori was found to be $125 \mu \mathrm{M}$ and therefore $100 \mu \mathrm{M}$ of piperine was used as the standard treatment level during infection and pretreatment of $H$. pylori. In both MOIs of 200 and 100, bacterial adhesion to the AGS cells was reduced up to $40 \%$ percent due to piperine treatment during infection and up to $25 \%$ in bacteria pretreated with piperine (Figure 2B), as determined by urease assay. Statistical analysis revealed that the piperine treatment during infection led to inhibition of bacterial adhesion $(\mathrm{p}<0.01)$ and inhibition of piperine-pretreated $H$. pylori adhesion $(p<0.05)$.

\section{Effect of piperine on adhesin and flagellar molecules expression}

H. pylori adhesion to the gastric epithelial is mediated by the adhesin molecules and the motility of the bacterium is driven by the flagella. As demonstated in the adhesion assay, $H$. pylori adhesion to gastric epithelial cells was inhibited significantly by the action of piperine. Therefore we performed RT-PCR to determine whether expression of the adhesin and flagellar genes was influenced by piperine. We tested the expression of adhesin genes hop $Z$, $b a b A, s a b A, h p a A, a l p A, a l p B$, and flagellar genes $f l h A$, $f l a A, f l a B$ and $f l g E$. Among these genes, flagellar integral membrane component encoding gene $f l h A$ and flagellar hook component encoding gene flgE expression was decreased dose dependently (Figure 4) in the bacteria treated with piperine, but the expression level of other molecules remained unchanged. 


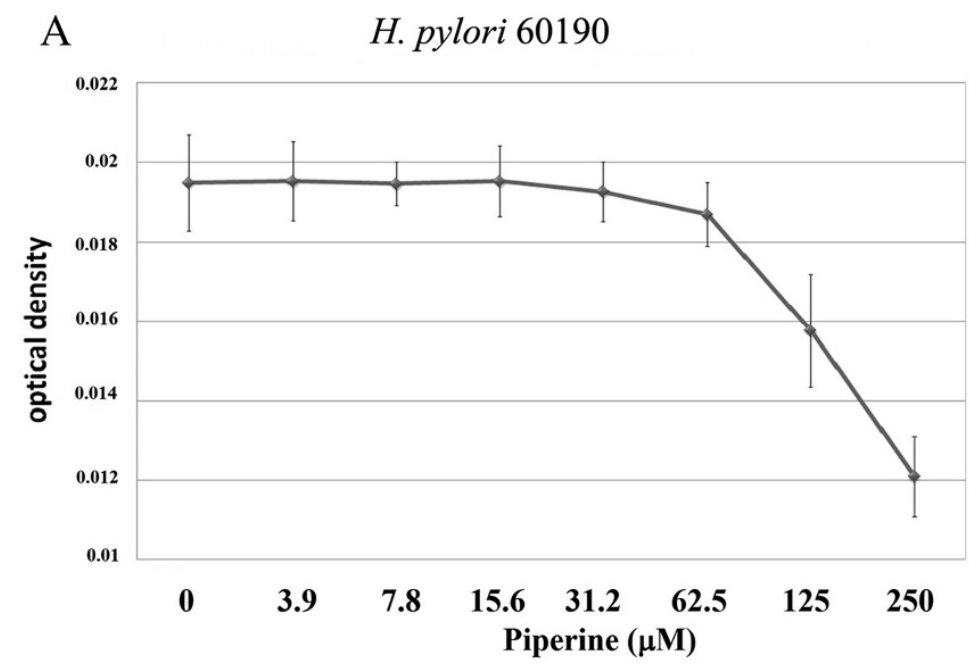

B

H. pylori NTCC 11637
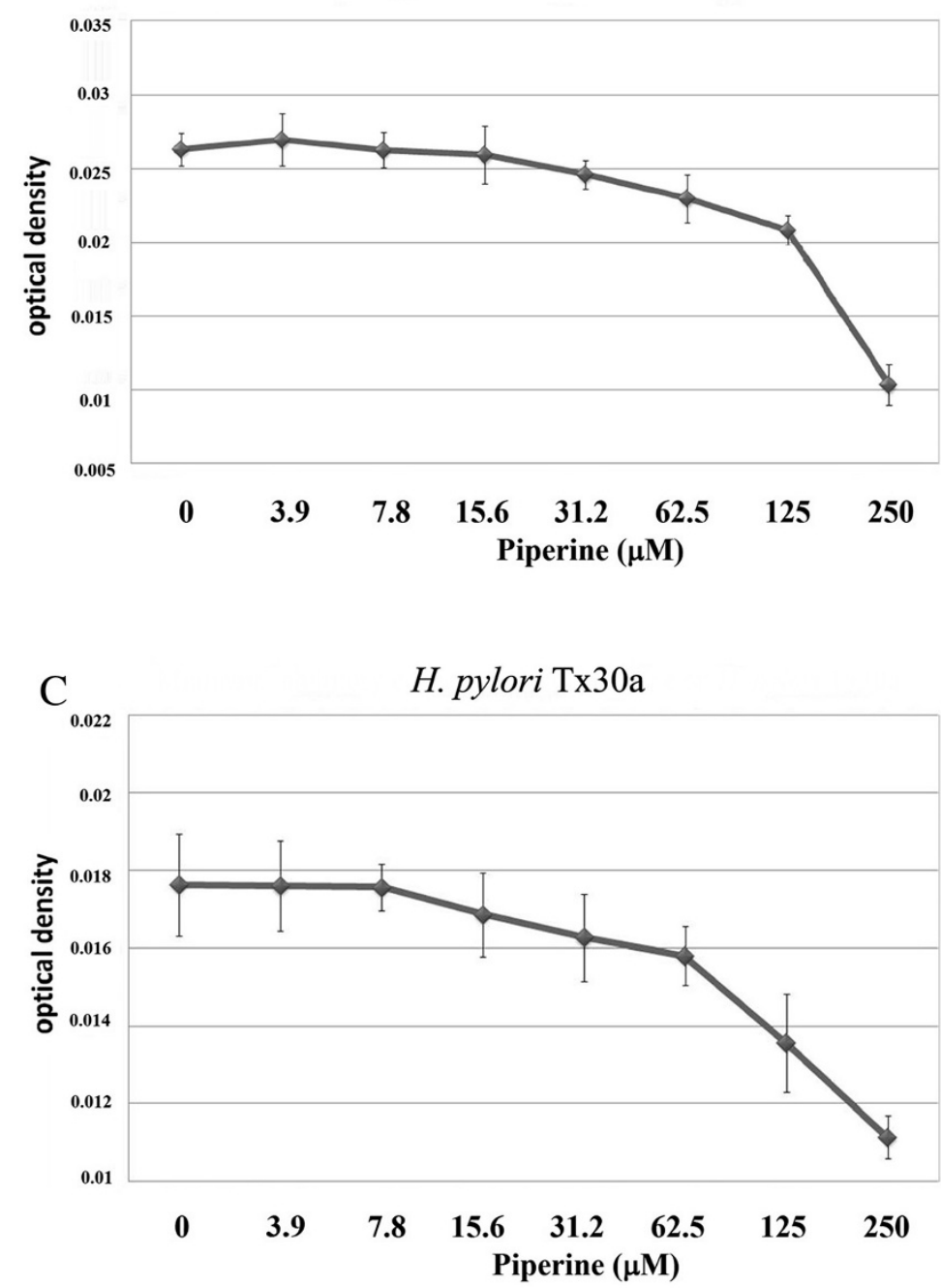

Figure 1 (See legend on next page.) 
(See figure on previous page.)

Figure 1 Growth inhibition of piperine on H. pylori strains. A) 60190; B) NCTC 11637; C) Tx30a. The growth inhibition was determined by the broth macrodilution method. Piperine concentrations from $3.9 \mu \mathrm{M}$ to $250 \mu \mathrm{M}$ were used in this growth inhibition assay compared to DMSO-treated control. Growth inhibition is expressed as optical density and $125 \mu \mathrm{M}$ concentration of piperine shows minimal inhibitory concentration on $\mathrm{H}$. pylori growth. The image is representative of three independent experiments and bars represent means \pm SEM.

\section{Effect of piperine on $\mathrm{H}$. pylori motility}

A motility agar containing $0.4 \%$ agar was used to determine the motility. $H$. pylori motility was abated in the medium, containing piperine compared to the DMSO containing control medium (Figure 5A). The swarming movement of the H. pylori decreased gradually at concentrations from $50 \mu \mathrm{M}$ and declined at a concentration of $100 \mu \mathrm{M}$ (Figure 5B-D).

\section{Protein levels of FlgE and FlhA}

RT-PCR results revealed that transcription of $f l g E$ and flhA was reduced by piperine treatment. To confirm this finding, we performed immunoblotting to determine whether the protein level of both protein molecules was diminished. Due to lack of specific antibodies to FlgE and FlhA, we used polyclonal rabbit anti- H. pylori whole cell antibody which we produced in our lab as described previously by Kim SH et al. [13]. The molecular weights of the H. pylori FlgE and FlhA are $77 \mathrm{KDa}$ and $81 \mathrm{KDa}$, respectively as determined from the Helicobase [14] - a specific database for $H$. pylori nucleic acid and protein sequences. Based on the predicted molecular weight, we observed the suppression of both FlgE and FlhA protein synthesis in piperine treated cells (Figure 6). Expression of other proteins was unchanged in both piperine treated and untreated normal control.

\section{Discussion}

In this study, we demonstrated the inhibitory effect of piperine on $H$. pylori growth and adhesion in gastric epithelial cells, which is the critical first step in the infection process. H. pylori is reported to be an organism whose drug resistance can increase over time [15]. At present, researchers are searching for bioactive compounds to treat bacterial infections due to an increase in drug resistance. Numerous reports have been published on various natural compounds and food supplements that inhibit H. pylori growth [16], adhesion [17] or toxin secretion [13]. The aim of our study was to explore an existing natural compound, which may act against $H$. pylori. Piperine has a known protective action against gastric ulcers [18]. It was observed that piperine inhibited $H$. pylori growth completely at concentrations of 125 and $250 \mu \mathrm{M}$. It was observed that $125 \mu \mathrm{M}$ is the minimal inhibitory concentration of piperine on $H$. pylori growth and it is recommended to determine the half maximal inhibitory concentration ( $\mathrm{IC}_{50}$ ) of piperine on $\mathrm{H}$. pylori. Based on the standard recommendations for the $\mathrm{IC}_{50}$ experiment, we observed that the $115 \mu \mathrm{M}$ of piperine was lethal to about $50 \%$ of cells. $\mathrm{IC}_{50}$ value was determined by the percentage of growth inhibition was plotted in a nonlinear regression curve. Results from both experiments shows that $125 \mu \mathrm{M}$ of piperine completely inhibited the H. pylori

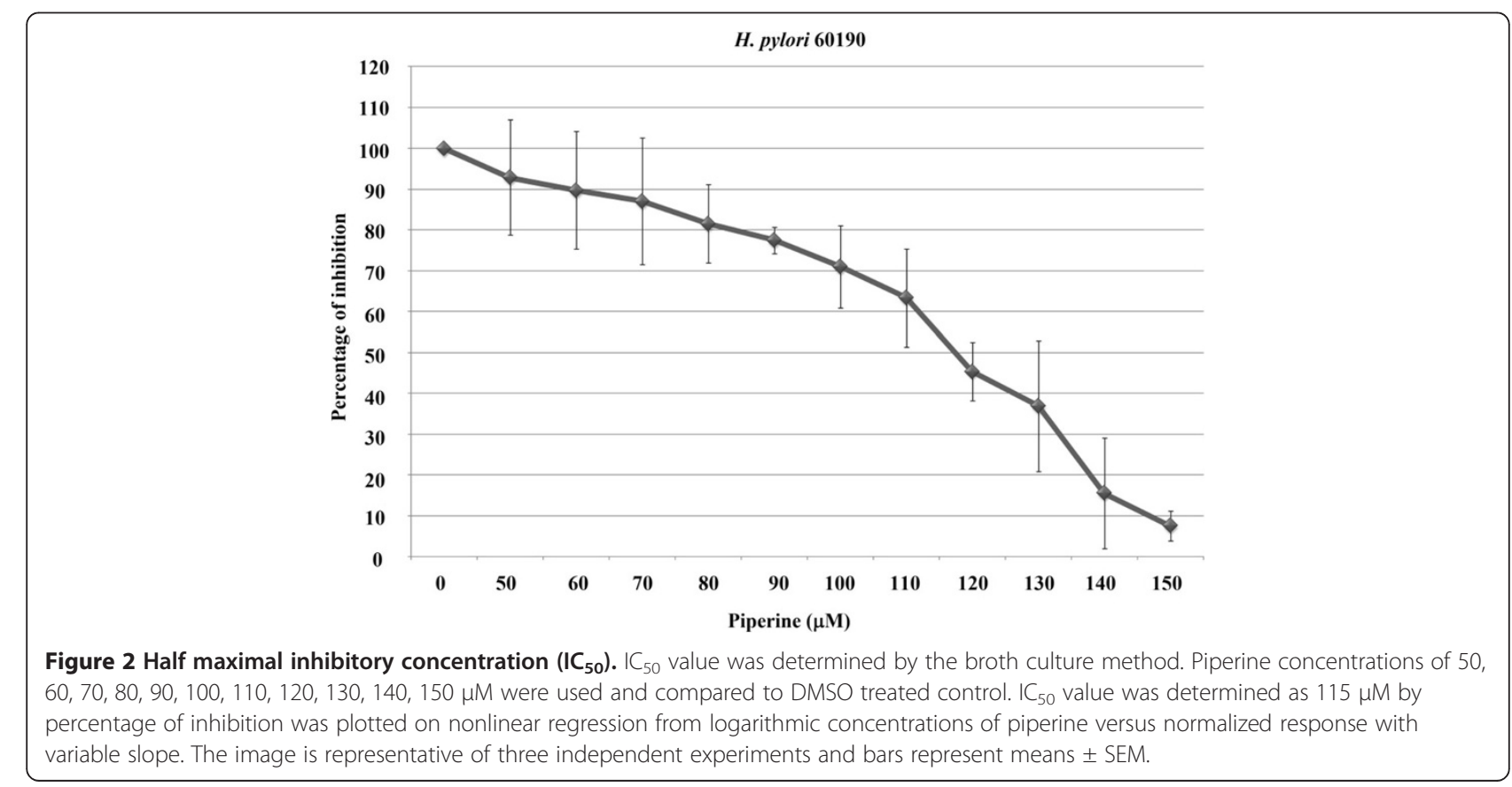




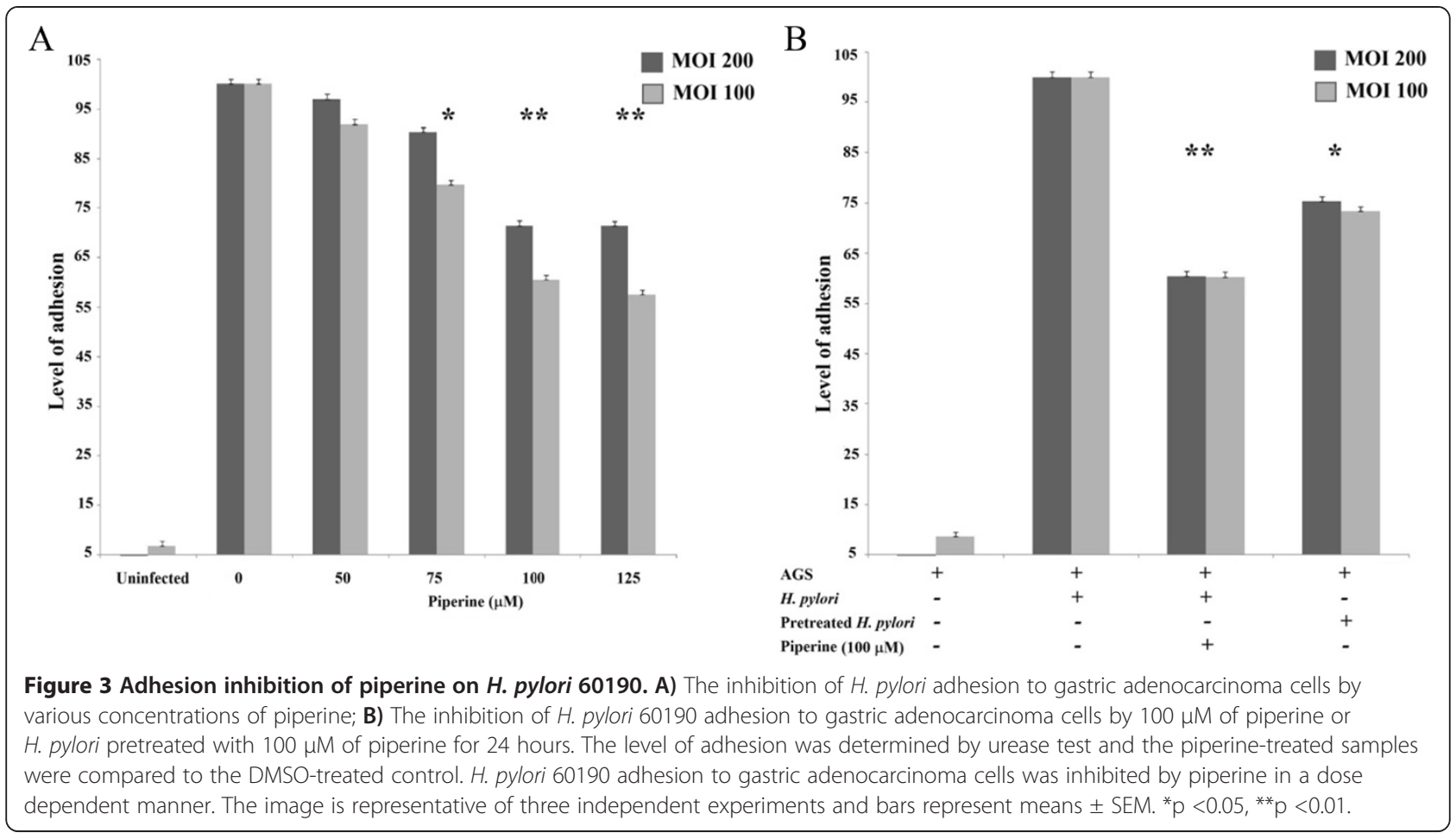

where as $115 \mu \mathrm{M}$ of piperine killed $50 \%$ of cells. Therefore, we used a $100 \mu \mathrm{M}$ concentration of piperine for subsequent experiments to uncover the inhibition mechanisms, such as adhesion and secretion of toxins. In this study, our data clearly shows that piperine inhibited $H$. pylori adhesion to gastric carcinoma cells. When $100 \mu \mathrm{M}$ of piperine was applied to $H$. pylori, attachment was reduced by up to $40 \%$. It was assumed that a piperine might obstruct $H$. pylori adhesion by blocking adhesion molecules such as, AlpA-B, BabA, SabA, HopZ, HpaA and Lewis ${ }^{\mathrm{x}}$-LPS, which would then lead to less adhesion to AGS cells compared to untreated bacteria. Another possibility is that piperine may influence the membrane proteins of AGS cells, which are the critical targets for $H$. pylori adhesion. Similarly, there was significant reduction in adhesion when organisms were pretreated with piperine for 24 hours, but the adhesion was slightly higher than that of piperine treatment during the infection. We assumed that the organism might be in an inactive state at subMIC level, but when it encountered fresh medium after the piperine treatment, it became more adherent than when piperine was administered during infection, but less than that of untreated control.

$H$. pylori adhesion inhibition by the action of piperine was determined by adhesion assay and this inhibitory mechanism was assessed by the RT-PCR, immunoblotting analysis and motility test. Six adhesion molecules and four flagellar molecules were tested to determine if the piperine had an influence on its expression. Expression of the six adhesion molecules $H$. pylori adhesin molecules were unchanged during the piperine treatment, but the expression of two flagellar molecules flh $A$ and $f l g E$ were found to be decreased (Figure 4) in a dose dependent manner. The biosynthetic molecule flhA, which is the positive regulator for the various molecules, particularly flaA and flaB and these genes, encodes flagellin, which is the subunit of the filament part of the flagella [6]. Though there was a decrease in $f l h A$ expression, we found no impairment in flaA and flaB expression. However, we observed decrease in the expression of $f l g E$, which encodes the subunit of the hook component of the flagella. Results from the previous experiments showed that the reduced adhesion and expression of flagellar molecules such as $f l h A$ and $f l g E$. RT-PCR data revealed that the suppression of transcription in $f l g E$ and flh $A$ due to the action of piperine in a dose dependent manner. To confirm this finding, we analyzed the expression of protein by immunoblotting. Immunoblot data also clearly showed suppression of both proteins due to piperine. Results from both experiments clearly show that piperine influences $f l g E$ and $f \ln A$ at the RNA and protein level, which leads to a less degree of infection. To confirm that the decrease in the expression of flagellar molecules by piperine exerted an effect, motility test was performed and the motility of the $H$. pylori 60190 was decreased dose dependently (Figure 5). It has been reported that $H$. pylori flagella is not involved in the bacterial adhesion, however the genes involved in the flagellar biosynthesis regulation also take part in regulating the production of adhesion molecules and 


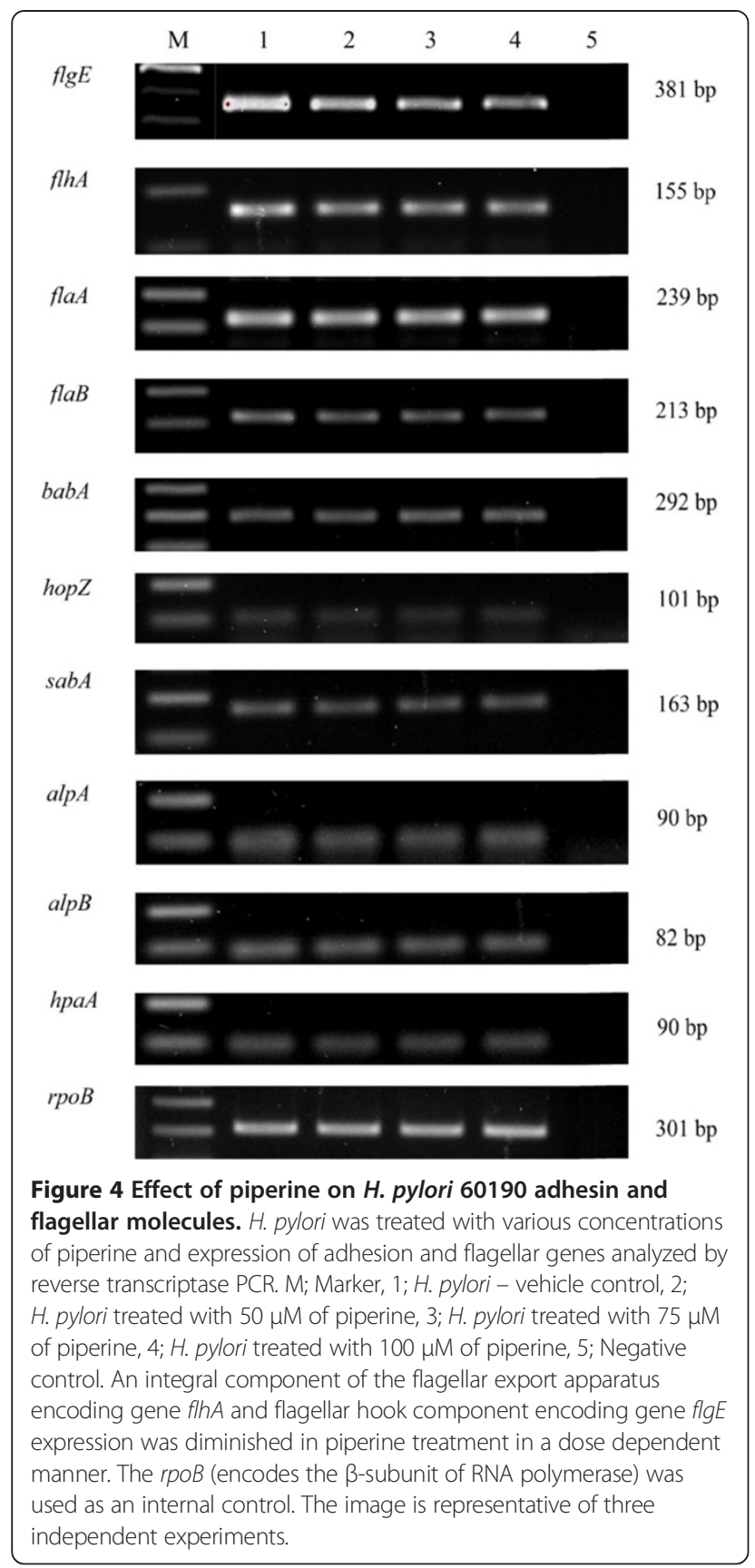

may regulate the bacterial adhesion [19]. Kao et al. [5], described that bacterial motility enhances the bacterial adhesion and is a good target for the control of bacterial colonization. Collectively, these results suggest that due to the suppression of the biosynthetic regulator gene flhA (integral membrane component of the export apparatus) and flagellar hook gene $f l g E$ because of piperine treatment may lead to the reduction in motility confirmed by the motility test. Due to decreased motility of H. pylori, the organism may be less attracted towards gastric epithelial cells, which results in the less adhesion compared with the untreated bacteria. As stated previously, piperine has been reported to have anticancer activities $[10,12]$. We believe that daily consumption of black pepper, which is comprised of 5-9\% piperine [20], reduces one's chance of infection and of developing gastric cancer caused by $H$. pylori. This report provides us a clue that impairment in the flagellar export system may lead to the defects in the plausible toxic protein injection and further detailed studies are in progress to better understand the complete mechanisms behind the inhibition of $H$. pylori adhesion to gastric epithelial cells followed by colonization and the action against $H$. pyloriinitiated oncogenesis by piperine.

\section{Conclusions}

In summary piperine inhibits $H$. pylori growth, and adhesion. Due to suppression in the flhA and flgE expression leads to decrease in motility. To the best of our knowledge, this is the first report showing the inhibition of $H$. pylori growth and adhesion to gastric adenocarcinoma cells by a single compound, piperine. Further studies are needed to analyze the reason behind the suppression of flagellar gene expression.

\section{Materials and methods}

Bacterial strains and mammalian cell culture

H. pylori reference strains 60190, NCTC 11637, Tx30a were purchased from American Type Cell Collection (ATCC, Manassas, VA, USA). Strains 60190 (ATCC 49503) and NTCC 11637 (ATCC 43504) express an intact and functional cagPaI and possess an $\mathrm{s} 1 / \mathrm{m} 1$ vacA toxin, whereas
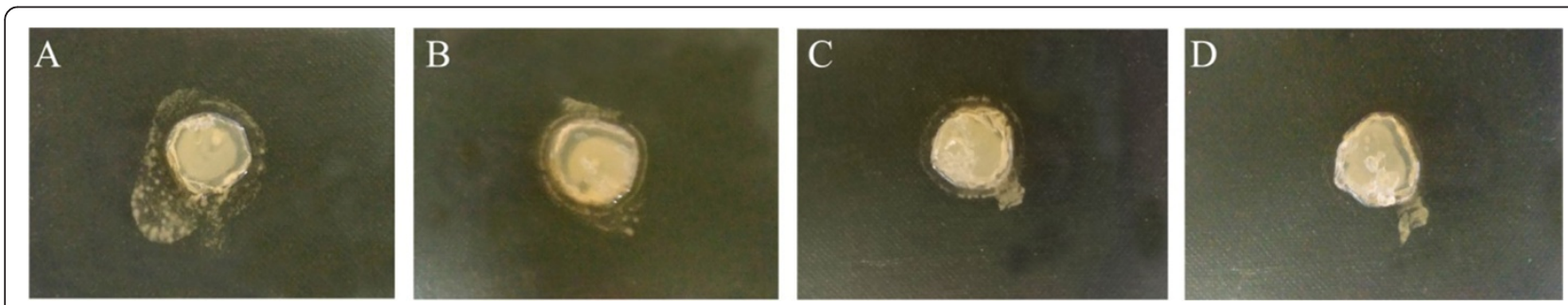

Figure 5 Motility inhibition of piperine on $\mathbf{H}$. pylori 60190. A) DMSO control; B) $50 \mu \mathrm{M}$ piperine; C) $75 \mu \mathrm{M}$ piperine; D) $100 \mu \mathrm{M}$ piperine. Agar grown $H$. pylori was inoculated on motility medium and after three days the motility inhibition was observed and photographed. The piperine treatment reduced motility at $100 \mu \mathrm{M}$ of piperine. 


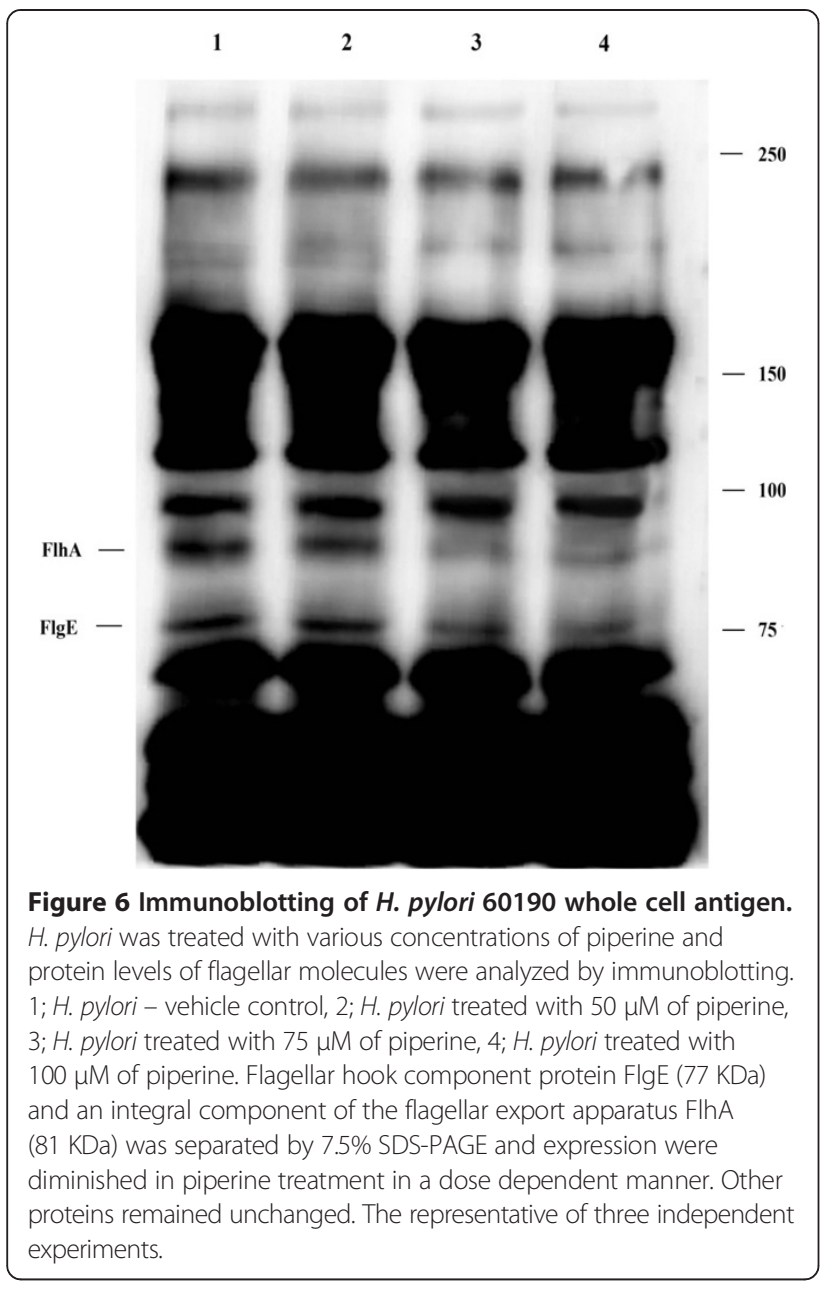

the strain Tx30a (ATCC 51932) expresses s2m2 vacA toxin, but does not possess the cagPaI. Bacteria were cultured on Brucella agar (Becton Dickinson, Braintree, MA, USA) supplemented with 10\% fetal bovine serum (FBS; Gibco, Long Island, NY, USA) and H. pylori selective supplement (vancomycin - $10.0 \mathrm{mg} / \mathrm{l}$, cefsulodin $-5.0 \mathrm{mg} / \mathrm{l}$, trimethoprim - $5.0 \mathrm{mg} / \mathrm{l}$, amphotericin B - $5.0 \mathrm{mg} / \mathrm{l}$ ) (Oxoid, Hampshire, England) in humidified incubators at $37^{\circ} \mathrm{C}$ under an atmosphere of $5 \% \mathrm{CO}_{2}$. AGS (gastric adenocarcinoma cell line) was purchased from the Korea Cell Line Bank (KCLB, Seoul, Korea) and cultured in Dulbecco's Modified Eagle's Medium (DMEM; Gibco) supplemented with $10 \%$ FBS and $100 \mu \mathrm{g} / \mathrm{ml}$ streptomycin, $100 \mathrm{U} / \mathrm{ml}$ penicillin (Gibco).

\section{Growth measurement}

The effect of piperine on $H$. pylori growth was determined by a broth macrodilution method [21] and the $H$. pylori bacterial inoculum was equipped with a turbidity comparable to that of a 0.5 McFarland standard $\left(1 \times 10^{8}\right.$ cells $)$ in Mueller Hinton broth (Becton Dickinson) supplemented with $10 \%$ FBS. A stock solution of $200 \mathrm{mM}$ piperine
(Sigma Aldrich, St. Louis, MO, USA) was dissolved in dimethyl sulfoxide (DMSO, Sigma Aldrich) and filtersterilized using a $0.20-\mu \mathrm{m}$ syringe filter. The working concentration was added directly to the broth to obtain a desired final concentration of the piperine $(250 \mu \mathrm{M})$. Subsequently, the broth was subjected to twofold serial dilution from $250 \mu \mathrm{M}$ to $3.9 \mu \mathrm{M}$ and incubated for three days under microaerophillic conditions. Vehicle control was maintained by adding equal concentrations of DMSO (alone) to a tube that contained the same number of cells as the experimental tubes, and did not show any inhibitory action on bacterial growth. After three days, the growth inhibition of piperine on $H$. pylori was determined by the optical density at $600 \mathrm{~nm}$ using a NanoQuant spectrophotometer (Infinite M200, (Tecan Austria GmbH, Grödig, Austria).

\section{Half maximal inhibitory concentration $\left(\mathrm{IC}_{50}\right)$}

H. pylori 60190 was used in this study. Agar grown $H$. pylori was suspended in Mueller Hinton broth supplemented with $10 \%$ FBS with a turbidity comparable to that of 0.5 McFarland standard $\left(1 \times 10^{8}\right.$ cells $)$. The concentration of piperine was incorporated between 50 to $150 \mu \mathrm{M}$ respectively. Incubation, optical density was followed as described in the growth measurement and the data was analyzed by GraphPad-Prism Analysis software (GraphPad-Prism Software Inc., San Diego, CA).

\section{Adhesion assay}

An adhesion test was performed as described by Rokka et al. [22], and for the infection studies, AGS cells were resuspended in DMEM and $1 \times 10^{4} / 100 \mu$ l cells were seeded in 96-well microtiter plates (Becton Dickinson) to form a confluent monolayer. $H$. pylori bacteria were harvested from three-day-old cultures on solid media and resuspended in PBS (Gibco). H. pylori bacteria were resuspended in antibiotic and serum free DMEM, which infected the monolayer that had been treated with various doses of piperine or pretreated with the sub-minimal inhibitory concentration of piperine for 24 hours. Pretreatment of $H$. pylori was equipped by agar grown bacteria suspended in sterile PBS and then resuspended in Brucella broth with $10 \%$ FBS at a turbidity value comparable to that of a 1.0 McFarland standard. Bacteria were then treated with $100 \mu \mathrm{M}$ of piperine for 24 hours before the cells were collected and resuspended in FBS and antibiotic free DMEM and used for infection. In this adhesion assay, multiplicity of infection (MOI) ratios of $1: 200$ and 1:100 were used to infect the AGS cells. After 2 hours of infection, the monolayer was washed three times with PBS to remove residual and unattached bacteria. A urease test was performed to analyze the quantity of bacteria that had adhered to the surface of the AGS cells. The urease test was carried out by adding $100 \mu \mathrm{L}$ of urease test solution 
(7 mM phosphate buffer pH 6.8, $110 \mathrm{mM}$ urea, $10 \mathrm{mg} / \mathrm{L}$ phenol red) into each well of microtiter plate. After a reaction time of 60 minutes, absorbance values at $540 \mathrm{~nm}$ were recorded with a NanoQuant spectrophotometer. The relative adhesion level was calculated by dividing the absorbance value of the sample with the absorbance value of a DMSO control containing the same amount of Helicobacter.

\section{Reverse transcriptase polymerase chain reaction}

H. pylori 60190 bacterial inoculum was equipped with a turbidity comparable to that of a 0.5 McFarland standard $\left(1 \times 10^{8}\right.$ cells $\left./ \mathrm{ml}\right)$ was grown in Brucella broth supplemented with $10 \%$ FBS in the presence or absence of piperine for three days at $37^{\circ} \mathrm{C}$ on a humidity chamber containing $\mathrm{CO}_{2}$ incubator. Various concentrations of piperine from 50, 75 and $100 \mu \mathrm{m}$ were treated to the bacteria, respectively and vehicle control was also maintained. Total RNA was extracted using TRIzol (Invitrogen, Carlsbad, CA, USA) and RNA concentration was determined by NanoQuant spectrophotometer. Expression of $H$. pylori adhesion molecules, flagellar molecules and rpoB (internal control) was determined by RT PCR. Two microgram of total RNA was mixed with $0.25 \mathrm{ng}$ of random hexamers (Invitrogen) and cDNA was synthesized using $200 \mathrm{U}$ of MMLV-RT (Invitrogen). PCR reactions were performed in a total volume of $20 \mu \mathrm{l}$ consisting of $2 \mu \mathrm{l}$ of $1 / 10$ diluted cDNA, $2 \mu \mathrm{l}$ of 10X PCR buffer (Tris- $\mathrm{HCl}$ [pH 9.0], $\left.20 \mathrm{mM} \mathrm{MgCl} 2,\left[\mathrm{NH}_{4}\right]_{2} \mathrm{SO}_{4}\right), 2.5 \mathrm{mM}$ dNTPs, 20 pmole of each primer, and 0.5 U G-Taq DNA polymerase (Cosmo Genetech, Seoul, Korea). PCR amplifications were carried out on a PTC-200 Peltier Thermal Cycler (BioRad, Toronto, Ontario) and PCR products were analyzed by electrophoresis on a $2.0 \%$ agarose gel containing $0.5 \mu \mathrm{g} / \mathrm{ml}$ of ethidium bromide. Gel images were captured and analyzed using the Quantity One System (Bio-Rad, Hercules, USA). The primer sequences and PCR conditions are listed in Table 1.

\section{Motility test}

Motility testing was performed as described by Suerbaum et al. [25]. In brief, Brucella agar supplemented with 10\% BSA (bovine serum albumin, Gibco) was used and two layered plates were prepared to determine the motility. Bottom layer contained 1.5\% agar, which poured on the plates followed by the soft upper layer contained $0.4 \%$ agar and piperine (50, 75, and $100 \mu \mathrm{M})$. Small slices of Brucella agar, which contained densely grown $H$. pylori 60190 was

Table 1 Primers used in this study

\begin{tabular}{|c|c|c|c|c|c|}
\hline Primer & Relevant sequence & Size of amplicon & Amplification cycles & Annealing temperature & References \\
\hline$f l g E-F$ & 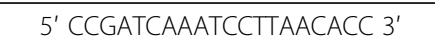 & 381 & 30 & 52 & This study \\
\hline flgE- R & 3' AGGCTTAAAAACATGCGAAC 5' & & & & \\
\hline flhA- F & 5' TCATTGGAGGGTIITTAGTGG 3' & 155 & 26 & 60 & {$[23]$} \\
\hline flhA- R & 3' GGTGCGAGTGGCGACAAT 5' & & & & \\
\hline flaA- F & 5' TAGACACCACCAACGCTAAA 3' & 239 & 28 & 62 & This study \\
\hline flaA- R & 3' TGCATTCTAGGGGGTTGTAT 5' & & & & \\
\hline$f l a B-F$ & 5' GTCAATGGCGTGAATGATTA 3' & 213 & 30 & 60 & This study \\
\hline flaB- R & 3' ATTCACGGTCCCAATTTCTA 5' & & & & \\
\hline$b a b A-F$ & 5' ATCGATCCACTTCCATCACT 3' & 292 & 40 & 48 & This study \\
\hline$b a b A-R$ & 3' GTTACGCTTTTGCCGTCTAT 5' & & & & \\
\hline hopZ- F & 5' GCGCCGTTACTAGCATGATCA 3' & 101 & 24 & 60 & [24] \\
\hline hopZ- R & 3' GAAATCTITCGGCGCGTIT 5' & & & & \\
\hline$s a b A-F$ & 5' AAAGCATTCAAAACGCCAAC 3' & 163 & 24 & 60 & This study \\
\hline$s a b A-R$ & $3^{\prime}$ CCCGCATAAAGACTCCAAAA 5' & & & & \\
\hline alpA-F & 5' GCACGATCGGTAGCCAGACT 3' & 90 & 22 & 60 & [24] \\
\hline alpA-R & 3' ACACATTCCCCGCATTCAAG 5' & & & & \\
\hline alpB- F & 5' ACGCTAAGAAACAGCCCTCAAC 3' & 82 & 26 & 60 & [24] \\
\hline$a l p B-R$ & 3' TCATGCGTAACCCCACATCA 5' & & & & \\
\hline hpaA- F & 5' GAGCGTGGTGGCTITGTTAGT 3' & 90 & 26 & 60 & [24] \\
\hline hpaA- R & 3' TCGCTAGCTGGATGGTAATTCA 3' & & & & \\
\hline rpoB- F & $5^{\prime}$ TTAGGTAAGCGCGTGGATT 3' & 301 & 27 & 59 & This study \\
\hline$r p o B-\mathrm{R}$ & 3' AATCAGCTTTGGATGGAACG 5' & & & & \\
\hline
\end{tabular}


inoculated by grown side of the agar slice facing the soft layer and incubated for three days under microaerobic condition [25].

\section{Immunoblotting}

H. pylori 60190 was used in this study. H. pylori treatment was followed as described before in RT- PCR. Cells were harvested then washed with sterile PBS and lysed by RIPA buffer (Millipore, Billerica, MA, USA) for 30 minutes on ice bath and sonicated for 2 minutes with 10 second intervals (Sonicator XL-2020, Heat Systems Ultrasonics, Pittsburgh, PA, USA) followed by centrifugation on 14, $000 \mathrm{RPM}$ for 15 minutes at $4^{\circ} \mathrm{C}$. Protein concentrations were determined by Lowri's method using NanoQuant spectrophotometer. Proteins were separated by sodium dodecyl sulfate polyacrylamide gel electrophoresis (SDS-PAGE) and transferred to BioTrace nitrocellulose membranes (Pall Corporation, Ann Arbor, MI, USA). Membranes were then blocked by $5 \%$ skim milk dissolved in PBS with $0.025 \%$ Tween 20 (PBST) then probed overnight with polyclonal rabbit anti- H. pylori whole cell antibody [13]. After washing with PBST, bound antibody was detected with a horseradish peroxidase conjugated anti-rabbit IgG secondary antibody (Santa Cruz Biotechnology, CA, USA). The blots were then developed by using EZ- Western Lumi Femto (Daeil lab service, Seoul, South Korea) and the signals were detected using a Fusion Solo Detector (Vilber Lourmat, Marne La Vallee, France).

\section{Statistical analysis}

Data were analyzed using the Student's $t$-test and expressed as mean values of at least three independent replications. Differences were considered to be highly statistically significant when $\mathrm{p}<0.01$ and significant at $\mathrm{p}<0.05$. The mean value of three independent experiments were analysed for $\mathrm{IC}_{50}$ was calculated by nonlinear regression from logarithmic concentrations of piperine Vs normalized response with variable slope using Graphpad Prism.

\begin{abstract}
Abbreviations
H. pylori: Helicobacter pylori; alpA, alpB: Adherence-associated lipoprotein A and B; babA: Blood group antigen-binding adhesion; sabA: Sialic acid-binding adhesion; hopZ: Helicobacter pylori outer membrane protein; hpaA: Helicobacter pylori adhesin A; flhA: Flagellar biosynthesis protein; flgE: Flagellar hook protein; flaA, Flab: Flagellin A and B; RT-PCR: Reverse transcriptase-polymerase chain reaction; sub-MIC: Subminimal inhibitory concentrations; DMSO: Dimethyl sulfoxide; DMEM: Dulbecco's modified eagle medium; FBS: Fetal bovine serum; BSA: Bovine serum albumin; MMLV-RT: Moloney murine leukemia virus- reverse transcriptase; $I_{50}$ : Half maximal inhibitory concentration; SDS-PAGE: Sodium dodecyl sulfate polyacrylamide gel electrophoresis; PBST: PBS with $0.025 \%$ Tween 20; RIPA buffer: Radio-immunoprecipitation assay buffer.
\end{abstract}

\section{Competing interests}

The authors declare that they have no competing interests.

\section{Authors' contributions}

NT main author of the study, design, performed experiments, analysis and preparation of the manuscript; SHK, MP, HJW, performed experimental support; HWK, JYY cultured bacterial strains; KJR, JBK were responsible for orientation and coordination of this study. All authors read and approved the final manuscript.

\section{Acknowledgements}

This work was supported by the Graduate School of Yonsei University and the BK 21 plus project, "Field-oriented Graduate Program for Biomedical and Molecular Diagnostics Professionals," in the Department of Biomedical Laboratory Science, Yonsei University.

\section{Author details}

'Department of Biomedical Laboratory Science, College of Health Sciences, Yonsei University, Wonju, Republic of Korea. ${ }^{2}$ Department of Clinical Laboratory Science, Semyung University, Jaecheon, Republic of Korea.

Received: 18 September 2014 Accepted: 19 November 2014 Published: 16 December 2014

\section{References}

1. Marshall BJ, Warren RJ: Unidentified curved bacilli in the stomach of patients with gastritis and peptic ulceration. Lancet 1984, 1(8390):1311-1315

2. Matsumoto $Y$, Marusawa H, Kinoshita K, Endo Y, Kou T, Morisawa T, Azuma T, Okazaki IM, Honjo T, Chiba T: Helicobacter pylori infection triggers aberrant expression of activation-induced cytidine deaminase in gastric epithelium. Nat Med 2007, 13(4):470-476.

3. Peek RM Jr, Blaser MJ: Helicobacter pylori and gastrointestinal tract adenocarcinomas. Nat Rev Cancer 2002, 2(1):28-37.

4. Odenbreit S: Adherence properties of Helicobacter pylori: impact on pathogenesis and adaptation to the host. Int J Med Microbiol 2005, 295(5):317-324.

5. Kao CY, Sheu BS, Wu JJ: CsrA regulates Helicobacter pylori $J 99$ motility and adhesion by controlling flagella formation. Helicobacter 2014. doi:10.1111/hel.12148.

6. Tsang J, Smith TG, Pereira LE, Hoover TR: Insertion mutations in Helicobacter pylori flhA reveal strain differences in RpoN-dependent gene expression. Microbiology 2013, 159:58-67.

7. Odenbreit S, Puls J, Sedlmaier B, Gerland E, Fischer W, Haas R: Translocation of Helicobacter pylori CagA into gastric epithelial cells by type IV secretion. Science 2000, 287(5457):1497-1500.

8. Ohnishi N, Yuasa H, Tanaka S, Sawa H, Miura M, Matsui A, Higashi H, Musashi M, Iwabuchi K, Suzuki M, Yamada G, Azuma T, Hatakeyama M: Transgenic expression of Helicobacter pylori CagA induces gastrointestinal and hematopoietic neoplasms in mouse. Proc Natl Acad Sci U S A 2008, 105(3):1003-1008.

9. Kunnumakkara AB, Koca C, Dey S, Gehlot P, Yodkeeree S, Danda D, Sung B, Aggarwal $B B$ : Molecular targets and therapeutic uses of spices modern uses for ancient medicine. 1st edition. Edited by Aggarwal BB, Kunnumakkara AB. Singapore: World Scientific Publishing Co. Pte. Ltd; 2009:1-56.

10. Srinivasan K: Black pepper and its pungent principle-piperine: a review of diverse physiological effects. Crit Rev Food Sci Nutr 2007, 47(8):735-748.

11. Pradeep $C R$, Kuttan $G$ : Effect of piperine on the inhibition of lung metastasis induced B16F-10 melanoma cells in mice. Clin Exp Metastasis 2002, 19(8):703-708.

12. Ouyang DY, Zeng LH, Pan H, Xu LH, Wang Y, Liu KP: Piperine inhibits the proliferation of human prostate cancer cells via induction of cell cycle arrest and autophagy. Food Chem Toxicol 2013, 60:424-430.

13. Kim SH, Park M, Woo H, Tharmalingam N, Lee G, Rhee KJ, Eom YB, Han SI, Seo WD, Kim JB: Inhibitory effects of anthocyanins on secretion of Helicobacter pylori CagA and VacA toxins. Int J Med Sci 2012 9(10):838-842

14. Helicobacterium database (HelicoBase) - Helicobacter genomic resources and analytic tools. [http://helicobacter.um.edu.my/index.php/home/main]

15. Francesco VD, Giorgio F, Hassan C, Manes G, Vannella L, Panella C, lerardi E, Zullo A: Worldwide $\mathrm{H}$. pylori antibiotic resistance: a systematic review. J Gastrointestin Liver Dis 2010, 19(4):409-414.

16. Ali SM, Khan AA, Ahmed I, Musaddiq M, Ahmed KS, Polasa H, Rao LV, Habibullah CM, Sechi LA, Ahmed N: Antimicrobial activities of eugenol and cinnamaldehyde against the human gastric pathogen Helicobacter pylori. Ann Clin Microbiol Antimicrob 2005, 4:20. 
17. Burger O, Weiss E, Sharon N, Tabak M, Neeman I, Ofek I: Inhibition of Helicobacter pylori adhesion to human gastric mucus by a highmolecular-weight constituent of cranberry juice. Crit Rev Food Sci Nutr 2002, 42(S3):279-284.

18. Fu BY, Hong X: Protective action of piperine against gastric ulcer. Acta Pharmocol Sin 2000, 4:357-359.

19. Clyne M, Ocroinin T, Suerbaum S, Josenhans C, Drumm B: Adherence of isogenic flagellum-negative mutants of Helicobacter pylori and Helicobacter mustelae to human and ferret gastric epithelial cells. Infect Immun 2000, 68(7):4335-4339.

20. Bhardwaj RK, Glaeser H, Becquemont L, Klotz U, Gupta SK, Fromm MF: Piperine, a major constituent of black pepper, inhibits human $\mathrm{P}$ glycoprotein and CYP3A4.J Pharmacol Exp Ther 2002, 302(2):645-650

21. Clinical and Laboratory Standards Institute: Methods for Dilution Antimicrobial Susceptibility Tests for Bacteria that Grow Aerobically; Approved Standard. Wayne, PA: CLSI document; 2006:M7-A7.

22. Rokka S, Myllykangas RS, Joutsjoki V: Effect of specific colostral antibodies and selected lactobacilli on the adhesion of Helicobacter pylori on AGS cells and the Helicobacter-induced IL-8 production. S Scand I Immunol 2008, 68(3):280-286.

23. Shen F, Hobley L, Doherty N, Loh JT, Cover TL, Sockett RE, Hardie KR, Atherton JC: In Helicobacter pylori auto-inducer-2, but not LuxS/MccAB catalysed reverse transsulphuration, regulates motility through modulation of flagellar gene transcription. BMC Microbiol 2010, 10:210

24. Wang J, Wang WH, Li J, Liu FX: Celecoxib inhibits Helicobacter pylori colonization-related factors. World J Gastroenterol 2010, 16(7):846-853.

25. Suerbaum S, Josenhans C, Labigne A: Cloning and genetic characterization of the Helicobacter pylori and Helicobacter mustelae flaB flagellin genes and construction of $\mathrm{H}$. pylori flaA- and flaB-negative mutants by electroporation mediated allelic exchange. J Bacteriol 1993, 175(11):3278-3288.

doi:10.1186/1750-9378-9-43

Cite this article as: Tharmalingam et al:: Inhibitory effect of piperine on Helicobacter pylori growth and adhesion to gastric adenocarcinoma cells. Infectious Agents and Cancer 2014 9:43.

\section{Submit your next manuscript to BioMed Central and take full advantage of:}

- Convenient online submission

- Thorough peer review

- No space constraints or color figure charges

- Immediate publication on acceptance

- Inclusion in PubMed, CAS, Scopus and Google Scholar

- Research which is freely available for redistribution 